\title{
Téoros
}

Revue de recherche en tourisme

\section{Le tourisme ethnoculturel chez les autochtones}

\section{Jacques Dagenais}

Volume 17, numéro 2, été 1998

L'industrie touristique autochtone

URI : https://id.erudit.org/iderudit/1072279ar

DOI : https://doi.org/10.7202/1072279ar

Aller au sommaire du numéro

Éditeur(s)

Université du Québec à Montréal

ISSN

0712-8657 (imprimé)

1923-2705 (numérique)

Découvrir la revue

Citer ce document

Dagenais, J. (1998). Le tourisme ethnoculturel chez les autochtones. Téoros,

17(2), 45-45. https://doi.org/10.7202/1072279ar d'utilisation que vous pouvez consulter en ligne.

https://apropos.erudit.org/fr/usagers/politique-dutilisation/ 


\section{LE TOURISME ETHNOCULTUREL CHEZ LES AUTOCHTONES}

\section{Jacques Dagenais}

Le tourisme ethnoculturel comprend des activités qui mettent en valeur la culture et les traditions d'un groupe ethnique. Chez les autochtones, il s'agit d'un complément du tourisme d'aventure basé sur la culture et la découverte d'un mode de vie traditionnel qui s'harmonise avec la nature (histoire, art culinaire, artisanat, musique, chants, etc.).

Sous la trilogie $\approx$ Authenticité, Nature, Culture $\%$, le tourisme ethnoculturel chez les autochtones offre des activités pour tous les goûts:

- Visite de communautés autochtones, de musées, de centres d'interprétation. Rencontre d'artisans, de sculpteurs, de peintres, de fabricants de raquettes, de canots, de paniers d'écorce et de mocassins. Découverte de l'histoire : soirées autour du feu à écouter les traditions et les légendes. Découverte des bienfaits des plantes médicinales et de la spiritualité autochtone.

- Randonnée à pied, en canot, en traîneau à chiens, en raquettes, en motoneige, en avion de brousse.

- Safari-photos, séjour en forêt ou dans la toundra, descente de rivières, escalade de montagnes.

- Observation de la flore et de la faune : immenses troupeaux de caribous du nord du Québec et grande variété d'oiseaux, de mammiferres marins.

- Chasse, pêche, cueillette, dégustation de caribou, d'orignal, de castor, d'oie blanche, de truite, de saumon, de doré, de brochet, d'esturgeon, d'omble chevalier, de moules et autres.

\section{ORIGINE ET ÉVOLUTION}

Il y a à peine vingt ans, il était presque inconcevable de parler de tourisme chez les autochtones. Quelques communautés semi-urbaines (Wendake et Mashteuiatsh) recevaient des visiteurs, mais les seuls touristes que l'on rencontrait dans les régions éloignées, les premiers touristes en fait, étaient les travailleurs non autochtones (enseignants, infirmières et travailleurs de la construction).

Aujourd'hui, la situation a bien changé. Les trois éditions du raid Harricana (1989, $1990,1991)$ ont mis les autochtones du Québec sur la carte du monde. Comme cette course de motoneige traversait de nombreux territoires habités par des communautés autochtones, Harricana leur a donné une visibilité incroyable dans les médias européens.

\section{IMPORTANCE DU PHÉNOMĖNE}

Le tourisme d'aventure qui comprend le tourisme ethnoculturel autochtone est une activité à fort potentiel. Avec un taux de croissance évalué à $37 \%$ pour les cinq prochaines années (Tourisme Québec) il constitue l'un des produits touristiques les plus prometteurs des années 1990 .

Les autochtones sont conscients des répercussions que le développement du tourisme pourrait avoir pour eux en ce qui a trait à la création d'emplois. C'est un excellent moyen de stimuler une économie vacillante. Le tourisme oblige les intervenants autochtones à livrer un produit authentique et de qualité.

Ce produit touristique de haut de gamme justifie les efforts que les communautés doivent déployer pour assurer le maintien de leurs traditions. En effet, elles sont les premiers bénéficiaires des avantages socioculturels et économiques qui découlent d'un produit équilibré et fiable.

Les Européens s'intéressent beaucoup un tel produit en raison de sa diversité e de ses activités quatre saisons orientées sur la chasse, la pêche, la culture, l'écotourisme et la pluralité des nations autochtones. Ils considèrent ces derniers comme membres d'une société mondiale par leurs traditions, leur spiritualité et les régions exotiques qu'ils habitent.

L'aventure, le dépaysement, l'exotisme à son meilleur, les grands espaces, la nordicité de la destination, les nombreux lacs et rivières, les particularités du climat, de la flore et de la faune, sont autant d'aspects qui contribuent à la diversité et à la qualité du produit. Revivre l'étape de la colonisation et redécouvrir le nouveau monde est enfin possible.

La clientèle européenne est donc un marché à privilégier pour les destinations québécoises, en particulier autochtones.

L'authenticité est le créneau du tourisme ethnoculturel chez les autochtones, et un défi pour tous les intervenants concernés.

Jacques Dagenais est conseiller en tourisme auprès du SACO (Service d'Aide Canadien aux Organismes). Depuis 1996, il collabore avec la Société touristique Innu au développement du tourisme ethnoculturel chez les autochtones du Quebec. 